\title{
Perancangan Aplikasi Pembelajaran Bahasa Mandarin Dasar Menggunakan Metode Unified Software Development Process
}

\author{
Andri Kulung $^{1}$, Steven Sentinuwo ${ }^{2}$, Alicia Sinsuw ${ }^{3}$ \\ 1,2,3 Jurusan Teknik Elektro FATEK UNSRAT \\ 120216128@student.unsrat.ac.id ${ }^{1}$,steven@unsrat.ac.id ${ }^{2}$, alicia.sinsuw@unsrat.ac.id ${ }^{3}$
}

\begin{abstract}
Abstrak - Bahasa Mandarin merupakan salah satu Bahasa yang terkenal di seluruh dunia. Ada sekitar 1.302 juta orang dengan berbagai kalangan umur telah menggunakan Bahasa mandarin, sehingga karena alasan tersebut banyak sekolah termasuk Sekolah Dasar (SD) Advent 1 Tikala Manado telah memasukkan Bahasa Mandarin sebagai salah satu mata pelajaran Bahasa asing. Namun siswa-siswa SD Advent 1 Tikala Manado merasa kesulitan dalam mempelajari Bahasa Mandarin dikarenakan tidak adanya media pembelajaran yang dapat membantu mereka dalam mempelajari Bahasa Mandarin di luar jam sekolah.

Aplikasi pembelajaran Bahasa Mandarin Dasar merupakan solusi untuk membantu siswa SD Advent 1 Tikala Manado dalam mempelajari Bahasa Mandarin, baik dalam proses pembelajaran di sekolah maupun di luar sekolah. Unified Software Development Process (USDP) merupakan metode pengembangan perangkat lunak yang prosesnya dikendalikan oleh Use Case (use case driven) dan dikerjakan secara berulang (iterative) sehingga pada akhirnya menghasilkan perangkat lunak terintegrasi berukuran besar yang terbentuk secara bertahap (Incremental) dengan bantuan Unified Modeling Language (UML) sebagai alat bantu utama analisis dan perancangan sistem perangkat lunak.

Aplikasi pembelajaran Bahasa Mandarin Dasar dibuat dengan fitur belajar dan bermain. Fitur belajar dilengkapi dengan materi pengajaran yang digolongkan ke dalam beberapa kategori yaitu kategori kelas 1, kelas 2, dan kelas 3 serta sub fitur berupa suara dengan tujuan siswa bisa mengetahui cara pengucapan suatu kata. Dengan dibuatnya aplikasi ini diharapkan agar aplikasi ini bisa membantu siswa dalam mempelajari Bahasa Mandarin pada jam sekolah maupun diluar jam sekolah.
\end{abstract}

Kata kunci: Aplikasi Pembelajaran, Bahasa Mandarin, Pengembangan perangkat lunak, Sekolah Dasar, USDP, UML.

\section{PENDAHULUAN}

Bahasa merupakan salah satu alat untuk berkomunikasi yang sangat penting di era globalisasi. Di era ini seseorang dituntut untuk dapat menguasai lebih dari satu bahasa asing guna meningkatkan sumber daya manusia dalam menghadapi daya saing yang semakin ketat. Disamping bahasa Inggris yang merupakan bahasa
Internasional, bahasa Mandarin pun telah menjadi salah satu bahasa asing yang banyak digunakan.

Pada bidang pendidikan, Bahasa mandarin telah menjadi salah satu mata pelajaran, meskipun ada banyak buku-buku penunjang pembelajaran bahasa Mandarin namun tidak serta memberikan kemudahan dalam mempelajari bahasa Mandarin secara langsung. Disamping itu tidak adanya suatu media pembelajaran yang sesuai dengan kebutuhan apa yang siswa inginkan. Bagi siswa dalam mempelajari Bahasa Mandarin bukan hal yang mudah, karena Bahasa Mandarin memiliki ciri khas pelafalan dan intonasi nada dengan goresan tulisan yang bervariasi.

Salah satu upaya untuk mempermudah siswa dalam mempelajari Bahasa Mandarin adalah dengan memanfaatkan teknologi. Teknologi tersebut berupa suatu aplikasi pembelajaran Bahasa Mandarin yang dirancang untuk membantu siswa dalam mempelajari Bahasa Mandarin. Aplikasi pembelajaran adalah media yang dapat digunakan untuk menyampaikan isi materi yang melibatkan perangkat bergerak seperti ponsel, laptop dan tablet PC.

Dengan permasalahan tersebut, maka topik ini diambil untuk membuat tugas akhir dengan judul "Perancangan Aplikasi Pembelajaran Bahasa Mandarin Dasar menggunakan Metode Unified Software Development Process".

\section{LANDASAN TEORI}

\section{A. Aplikasi Pembelajaran}

Aplikasi pembelajaran merupakan program yang berfungsi sebagai alat, bahan atau teknik yang digunakan dalam kegiatan belajar mengajar dengan maksud agar proses interaksi komunikasi edukasi antara guru dan siswa dapat berlangsung secara tepat guna dan berdayaguna. Aplikasi pembelajaran memiliki manfaat yang besar mempermudah siswa dalam mempelajari materi ajar. Aplikasi pembelajaran yang digunakan juga harus dapat menarik perhatian siswa agar lebih menarik minat siswa untuk belajar ${ }^{[3]}$

\section{B. Unity}

Unity merupakan ekosistem pengembangan game: mesin render yang kuat terintegrasi dengan satu set lengkap alat intuitif dan alur kerja yang cepat untuk membuat konten $3 \mathrm{D}$ interaktif, penerbitan multiplatform yang mudah, ribuan kualitas, aset siap pakai di Asset Store dan berbagi 
pengetahuan di komunitas. Unity secara rinci dapat digunakan untuk membuat video game $3 \mathrm{D}$, real time animasi 3D dan visualisasi arsitektur dan isi serupa yang interaktif lainnya.

\section{Bahasa Mandarin}

Bahasa Mandarin merupakan bahasa yang tidak menggunakan abjad latin dalam sistem penulisannya, oleh karena itu tanpa adanya sistem penulisan latin akan sulit bagi orang asing untuk mempelajari bahasa Mandarin ${ }^{[2]}$

Mandarin berarti "Beifanghua" (secara harafiah berarti "bahasa percakapan Utara"), yang merupakan sebuah kategori yang luas yang mencakup beragam jenis dialek percakapan Tionghoa yang digunakan sebagai bahasa lokal di sebagian besar bagian utara dan barat daya Tiongkok, dan menjadi dasar bagi "Putonghua" dan "Guoyu". "Beifanghua" mempunyai lebih banyak penutur daripada bahasa apapun yang lainnya dan terdiri dari banyak jenis termasuk versi-versi yang sama sekali tidak dapat dimengerti ${ }^{[1]}$.

\section{Pengucapan Bahasa Mandarin}

Dalam pengucapannya, setiap kata dalam bahasa Mandarin mengalami perubahan nada. Perubahan nada ini dinamakan yindiao (音调). Intonasi adalah yang sangat vital, yang berfungsi sebagai alat untuk membedakan antara silabel satu dengan yang lainnya atau kata-kata yang identik. Bahasa Mandarin mempunyai 4 nada yang berbeda dan satu nada netral yang dapat dilihat pada Gambar 1. Empat nada yang berbeda dinamakan sisheng (四声) dan nada yang netral dinamakan qingsheng (轻声 $)^{[5]}$.

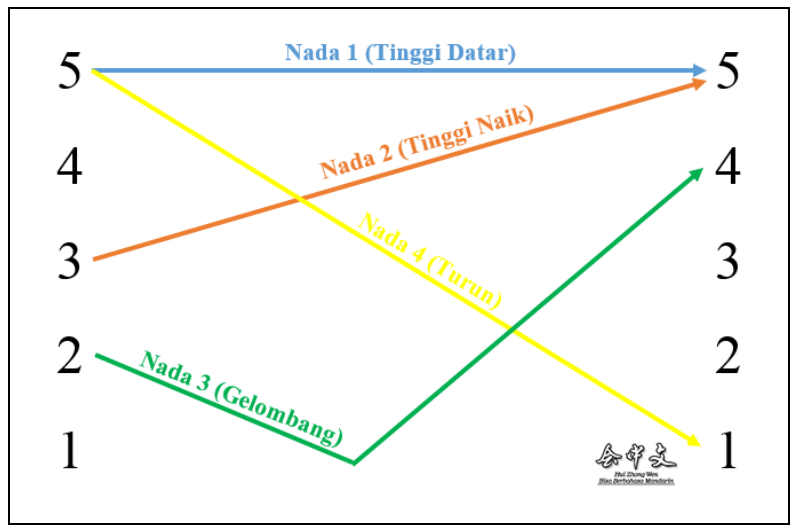

Gambar 1 Nada Pengucapan Bahasa Mandarin

\section{E. Unified Software Development Process}

Pada dasarnya pengembangan atau rekayasa perangkat lunak dapat berarti menyusun aplikasi yang benar-benar baru atau - yang lebih sering terjadi menyempurnakan yang telah ada sebelumnya ${ }^{[6]}$.Sehingga, dapat dikatakan bahwa mengembangkan perangkat lunak merupakan suatu proses berkelanjutan. Inilah prinsip pengembangan perangkat lunak. Untuk mengembangkan perangkat lunak secara berkelanjutan, diperlukan suatu kerangka kerja. Kerangka kerja pengembangan perangkat lunak ini memandang perangkat lunak sebagai suatu produk yang dihasilkan melalui suatu proses logis yang berurutan dengan masukan-masukan yang tepat. Inilah yang dimaksudkan dengan pendekatan process framework. System Development Life Cycle (disingkat SDLC) atau disebut Daur Hidup Pengembangan Sistem adalah kerangka kerja proses pengembangan perangkat lunak yang berkelanjutan. SDLC membagi tahapan pengembangan perangkat lunak menjadi: Tahap Komunikasi, Tahap Perencanaan, Tahap Pemodelan, Tahap Konstruksi dan Tahap Implementasi ${ }^{[4]}$.

USDP merupakan salah satu kerangka kerja pengembangan perangkat lunak berorientasi obyek. USDP, yang kemudian lebih dikenal dengan Unified Process (disingkat UP), dikembangkan oleh Graddy Booch, Ivar Jacobson dan James Rumbaugh. USDP merupakan metode pengembangan perangkat lunak yang berbasis komponen, yang berarti system perangkat lunak yang kelak dihasilkan akan terdiri atas komponen-komponen perangkat lunak yang saling terhubung melalui antarmuka yang terdefinisi dengan baik ${ }^{[4]}$.

\section{METODOLOGI PENELITIAN}

\section{A. Identifikasi Masalah}

Berdasarkan hasil pengamatan di Sekolah Dasar Advent 1 Tikala Manado, ditemukan masalah sebagai berikut:

1. Siswa kesulitan dalam mempelajari Bahasa Mandarin dikarenakan proses pembelajaran yang konvensional dimana guru menyampaikan materi secara langsung saat jam pelajaran berlangsung saja

2. Belum adanya media pembelajaran yang dapat digunakan siswa.

\section{B. Pengumpulan Data}

Metode pengumpulan data yang digunakan dalam penelitian ini adalah sebagai berikut :

1. Studi pustaka

Pada bagian ini peneliti melakukan kajian pustaka dengan membaca buku-buku dan hasil penelitian dari beberapa peneliti sebelumnya yang memilik hubungan dengan penelitian ini agar mendapat landasan teori mengenai masalah yang akan diteliti.

\section{Kuesioner}

Pada bagian ini peneliti menyebarkan kuesioner kebutuhan pengguna, kuesioner ini disebarkan dengan tujuan untuk menjawab pertanyaan apakah pengguna membutuhkan aplikasi ini atau tidak, dan untuk menentukan fitur-fitur dan sub fitur aplikasi yang akan dibangun nantinya. Penulis menyebarkan kuesioner ke 52 responden yang terdiri atas Siswa sekolah dasar kelas 1, 2, dan 3, Guru sekolah dasar, dan Orang tua siswa.

3. Wawancara

Pada bagian ini penulis melakukan wawancara kepada beberapa narasumber (Guru sekolah dasar, siswa sekolah dasar, dan orang tua), wawancara yang dilakukan pada bagian ini bertujuan untuk mendapatkan umpan balik terhadap aplikasi yang dibuat. 


\section{Metode Pemecahan Masalah}

Pada tahap ini penulis menggunakan 4 langkah USDP untuk perancangan aplikasi. Langkah tersebut terdiri dari inception, elaboration, contruction, transition. Untuk tahap construction dan transition akan dibahas pada bab selanjutnya.

\section{Inception}

Pada tahap ini peneliti melakukan analisis kebutuhan user.

Untuk mengetahui hal-hal apa saja yang dibutuhkan user maka pengembang menyebarkan kuesioner kebutuhan pengguna. Kuesioner disebarkan kepada 52 responden dengan target responden yang terdiri atas siswa sekolah dasar kelas 1, 2, dan 3, guru sekolah dasar, dan orang tua siswa.

\section{Elaboration}

Pada tahap ini dilakukan perancangan perangkat lunak mulai dari menspesifikan fitur perangkat lunak dengan pemodelan UML aplikasi (use case, class diagram, sequence diagram).

\section{a) Pemodelan UML}

\section{- Pemodelan Fungsional}

Semua fungsionalitas yang akan dibangun dalam aplikasi akan digambarkan menggunakan diagram use case. Use Case Diagram aplikasi pembelajaran Bahasa Mandarin dasar dapat dilihat pada Gambar 2.

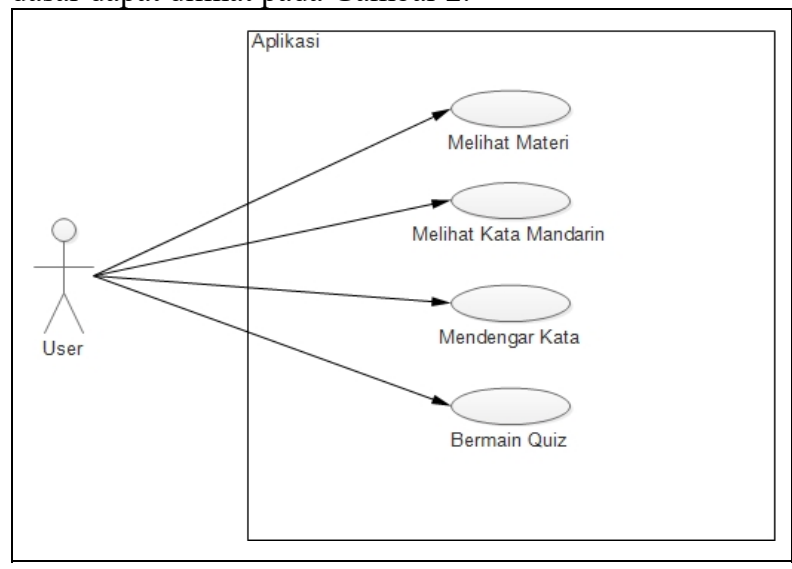

Gambar 2 Use Case Diagram aplikasi pembelajaran Bahasa Mandarin dasar

Setelah semua fungsionalitas digambarkan, selanjutnya adalah mendeskripsikan setiap fungsi yang ada. Fungsi yang pertama adalah melihat materi. Deskripsi use case dari fungsi melihat materi dapat dilihat pada tabel 1.

Tabel 1 Deskripsi use case melihat materi

\begin{tabular}{|l|l|}
\hline Use Case ID: & 1 \\
\hline Use Case Name: & Melihat Materi \\
\hline Actors: & User \\
\hline Description: & $\begin{array}{l}\text { User melihat materi pada } \\
\text { aplikasi }\end{array}$ \\
\hline Preconditions: & - \\
\hline
\end{tabular}

\begin{tabular}{|l|l|}
\hline Postconditions: & $\begin{array}{l}\text { 1- User melihat materi kelas } \\
1,2, \text { dan } 3\end{array}$ \\
\hline Normal Flows: & $\begin{array}{l}\text { 1- Buka aplikasi } \\
\text { 2- Pilih menu belajar }\end{array}$ \\
\hline Alternative Flows: & $\begin{array}{l}\text { 2a. Materi yang dicari User } \\
\text { tidak ada } \\
1-\quad \text { User mencari materi } \\
\text { yang lain. }\end{array}$ \\
\hline Exceptions: & - \\
\hline
\end{tabular}

Fungsi yang kedua adalah fungsi melihat kata, pada fungsi ini user dapat melihat kata dalam Bahasa Mandarin dari setiap materi yang dipilih. Deskripsi use case dari fungsi melihat kata dapat dilihat pada tabel 2 .

Tabel 2 Deskripsi use case melihat kata

\begin{tabular}{|l|l|}
\hline Use Case ID: & 2 \\
\hline Use Case Name: & Melihat Kata \\
\hline Actors: & User \\
\hline Description: & $\begin{array}{l}\text { User melihat kata yang } \\
\text { terdapat di materi kelas 1, 2, } \\
\text { atau 3 pada aplikasi }\end{array}$ \\
\hline Preconditions: & $\begin{array}{l}\text { User membuka menu materi } \\
\text { terlebih dahulu }\end{array}$ \\
\hline Postconditions: & $\begin{array}{l}\text { 1- User melihat kata pada } \\
\text { materi }\end{array}$ \\
\hline Normal Flows: & $\begin{array}{l}\text { 1- Buka aplikasi } \\
\text { 2- Pilih menu belajar } \\
\text { 3- Pilih kelas dan materi yang } \\
\text { akan dipelajari }\end{array}$ \\
\hline Alternative Flows: & $\begin{array}{l}\text { 3a. Kata pada aplikasi tidak } \\
\text { ada }\end{array}$ \\
\hline Exceptions: & \multicolumn{1}{c|}{ 1- User mencari materi } \\
\hline
\end{tabular}

Fungsi yang ketiga adalah fungsi mendengar kata, pada fungsi ini user dapat mendengar kata dalam Bahasa Mandarin dan Bahasa Indonesia dari setiap kata yang tersedia. Deskripsi use case dari fungsi mendengar kata dapat dilihat pada tabel 3 .

Tabel 3 Deskripsi use case mendengar kata

\begin{tabular}{|l|l|}
\hline Use Case ID: & 3 \\
\hline Use Case Name: & Mendengar Kata \\
\hline Actors: & User \\
\hline Description: & $\begin{array}{l}\text { User mendengar kata dalam } \\
\text { bahasa Mandarin dan } \\
\text { Indonesia }\end{array}$ \\
\hline Preconditions: & $\begin{array}{l}\text { User membuka menu materi } \\
\text { terlebih dahulu }\end{array}$ \\
\hline Postconditions: & $\begin{array}{l}\text { 1- User melihat kata pada } \\
\text { materi }\end{array}$ \\
\hline Normal Flows: & $\begin{array}{l}\text { 1- Buka aplikasi } \\
\text { 2- Pilih menu belajar } \\
\text { 3- Pilih kelas dan materi yang } \\
\text { akan dipelajari } \\
\text { 4- Tekan tombol pada kata } \\
\text { untuk mendengar kata dalam } \\
\text { bahasa Mandarin dan } \\
\text { Indonesia }\end{array}$ \\
\hline
\end{tabular}




\begin{tabular}{|c|c|}
\hline Alternative Flows: & $\begin{array}{l}\text { 3a. Kata pada aplikasi tidak } \\
\text { ada } \\
\begin{array}{ll}\text { 1- } & \text { User mencari materi } \\
& \text { yang lain. }\end{array}\end{array}$ \\
\hline Exceptions: & - \\
\hline
\end{tabular}

Fungsi yang keempat adalah fungsi bermain quiz, pada fungsi ini user dapat bermain mini game yang berupa quiz pemahaman dari materi yang telah dipelajari. Deskripsi use case dari fungsi bermain quiz dapat dilihat pada tabel 4 .

Tabel 4 Deskripsi use case bermain quiz

\begin{tabular}{|l|l|}
\hline Use Case ID: & 4 \\
\hline Use Case Name: & Bermain Quiz \\
\hline Actors: & User \\
\hline Description: & $\begin{array}{l}\text { User bermain quiz memilih } \\
\text { kata yang sesuai dengan } \\
\text { gambar }\end{array}$ \\
\hline Preconditions: & - \\
\hline Postconditions: & $\begin{array}{l}\text { 1- User bermain quiz memilih } \\
\text { kata }\end{array}$ \\
\hline Normal Flows: & $\begin{array}{l}\text { 1- Buka aplikasi } \\
\text { 2- Pilih menu bermain } \\
3-\text { Tekan tombol mulai untuk } \\
\text { memulai permainan }\end{array}$ \\
\hline Alternative Flows: & - \\
\hline Exceptions: & - \\
\hline
\end{tabular}

Dokumentasi dari use case aplikasi pembelajaran Bahasa Mandarin Dasar dapat dilihat pada tabel 5

Tabel 5 Dokumentasi use case aplikasi pembelajaran Bahasa mandarin Dasar

\begin{tabular}{|c|c|l|}
\hline No. & Aktor & \multicolumn{1}{c|}{ Use Case } \\
\hline 1 & User & $\begin{array}{l}\text { Dapat melihat materi, melihat kata } \\
\text { pada materi, mendengar kata pada } \\
\text { materi, dan bermain permainan } \\
\text { mencocokkan kata dengan gambar }\end{array}$ \\
\hline
\end{tabular}

- Pemodelan Objek/Struktur

Pada bagian ini, dijelaskan mengenai penggunaan Class Diagram. Pada gambar 4.32, terlihat bahwa hanya terdapat 2 kelas, yaitu user dan aplikasi. User memiliki fungsi untuk mengakses aplikasi, sedangkan Sistem memiliki fungsi untuk menampilkan kata atau materi, dan memutar suara dari kata yang dipilih. Kelas Sistem memiliki atribut berupa kata, materi, dan suara.

\section{Class Diagram Aplikasi}

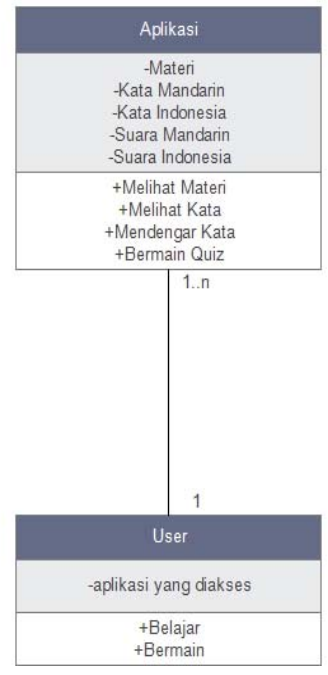

Gambar 3 Diagram kelas aplikasi pembelajaran Bahasa mandarin Dasar

- Pemodelan Behavior

Pada bagian ini, dijelaskan mengenai proses dari apliaksi yang berjalan dengan menggunakan sequence diagram. Proses utama dari aplikasi dapat dilihat pada gambar 4.

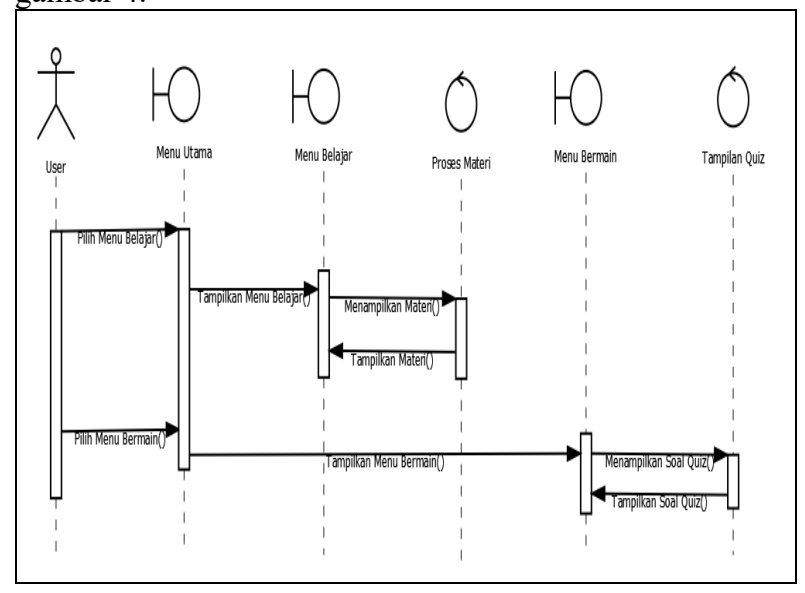

Gambar 4 Sequence Diagram aplikasi pembelajaran Bahasa Mandarin dasar

\section{HASIL DAN PEMBAHASAN}

\section{A. Construction}

Pengimplentasian rancangan perangkat lunak yang telah dibuat dilakukan pada tahap ini. Dalam pembuatan aplikasi, pengembang menggunakan Unity.

Hal yang pertama dilakukan sebelum membuat aplikasinya adalah mengimport semua objek yang akan digunakan dengan cara memilih menu Assets > import package $>$ custom package, bisa juga dengan cara drag and drop langsung ke menu assets. Setelah semua objek di 
import, langkah selanjutnya adalah membuat scene dengan cara memilih menu Assets $>$ create $>$ scene.

Setelah scene selesai dibuat, langkah selanjutnya adalah membuat tampilan dari setiap scene, scene yang pertama adalah scene menu utama. Pada tampilan ini pengembang membuat 4 tombol. Tombol yang pertama adalah tombol belajar dimana ketika pengguna memilih tombol ini maka sistem akan menampilkan scene belajar, tombol yang kedua adalah tombol bermain yang ketika dipilih maka sistem akan menampilkan scene bermain, tombol yang ketiga adalah tombol tentang yang ketika dipilih sistem akan menampilkan scene tentang yang berisi tentang aplikasi dan pembuat, tombol yang keempat adalah tombol keluar yang berfungsi untuk keluar dari apliaksi. Pada tampilan ini pengembang menambahkan objek slider yang berfungsi untuk control volume. Untuk hasil pembuatan Scene menu utama bisa dilihat pada Gambar 5.

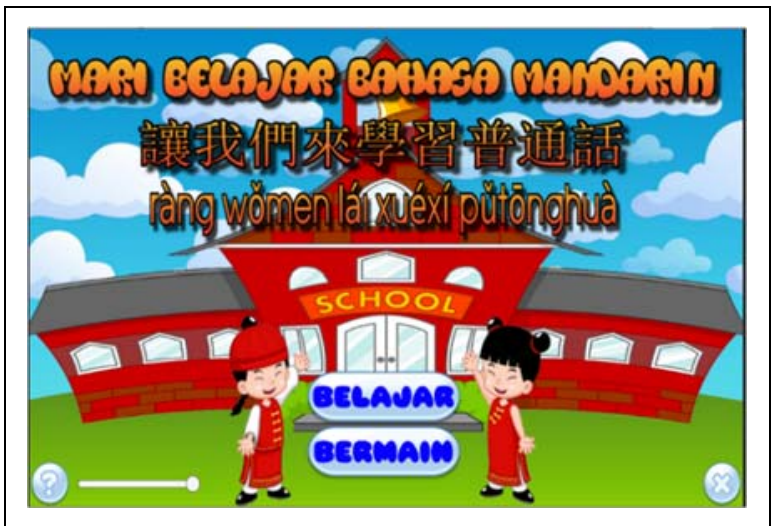

Gambar 5 Pembuatan Scene menu utama

Scene kedua adalah scene belajar. Pada tampilan ini pengembang membuat panel kelas yang berisi pilihan kelas (kelas 1, kelas 2, kelas 3), panel pemilihan materi yang berisi pilihan materi yang tersedia dari setiap kelas yang dipilih, panel tampilan materi yang berisi tampilan dari setiap materi yang dipilih, dan tombol kembali untuk kembali ke menu utama. Isi dari panel pilihan materi akan berbeda sesuai dengan kelas yang dpilih, begitu juga dengan panel tampilan materi akan berbeda sesuai dengan materi yang dipilih. Untuk hasil pembuatan Scene belajar utama bisa dilihat pada Gambar 6 .

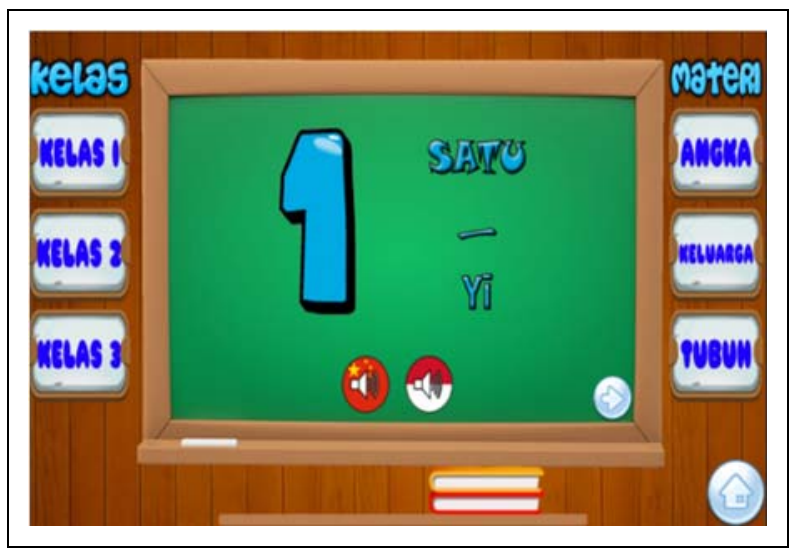

Gambar 6 Pembuatan Scene belajar
Scene ketiga adalah scene bermain. Pada tampilan ini akan terdiri dari teks aturan bermain, tombol mulai bermain untuk memulai permainan yang berupa kuis, dan tombol kembali untuk kembali ke menu utama. Untuk hasil pembuatan Scene bermain bisa dilihat pada Gambar 7 .

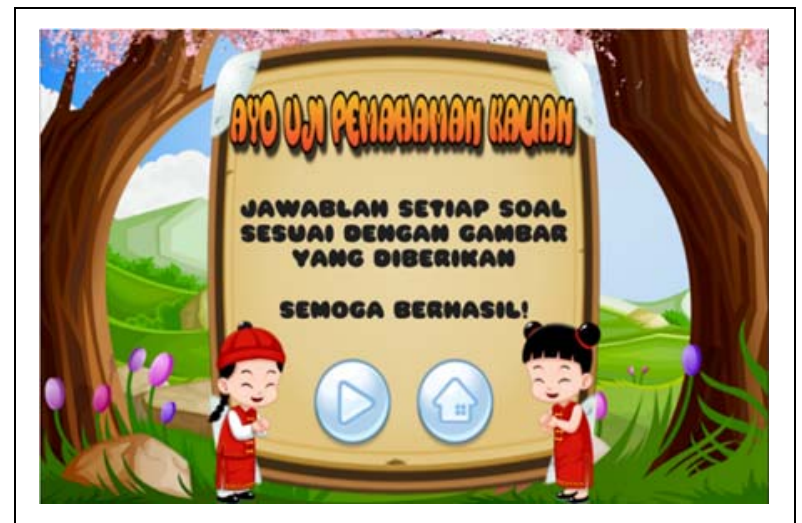

Gambar 7 Pembuatan Scene bermain

Scene keempat adalah scene mulai bermain. Pada tampilan ini terdapat 2 panel, 4 tombol pilihan jawaban dan 1 tombol kembali yang berfungsi untuk kembali ke menu utama. Panel yang pertama adalah panel level yang berisi tingkatan level, panel yang kedua adalah panel gambar yang berisi gambar pertanyaan yang harus dijawab pengguna dengan memilih salah satu pilihan dari tombol pilihan jawaban. Untuk hasil pembuatan Scene mulai bermain bisa dilihat pada Gambar 8.

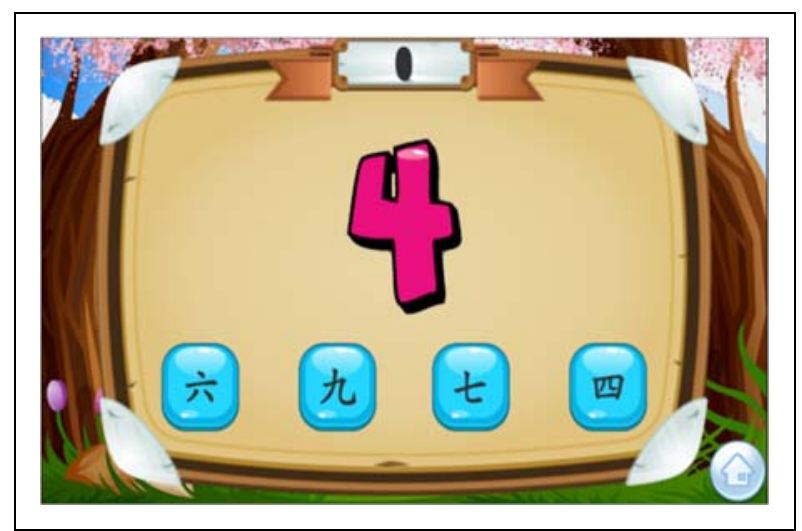

Gambar 8 Pembuatan Scene mulai bermain

Scene kelima adalah scene berhasil. Pada tampilan scene ini terdapat teks ucapan selamat kepada pengguna yang telah berhasil menjawab semua pertanyaan dengan benar, dan terdapat 2 tombol, tombol yang pertama adalah tombol coba lagi yang berfungsi untuk bermain lagi dari awal dan tombol kembali untuk kembali ke menu utama. Untuk hasil pembuatan Scene berhasil bisa dilihat pada Gambar 9. 


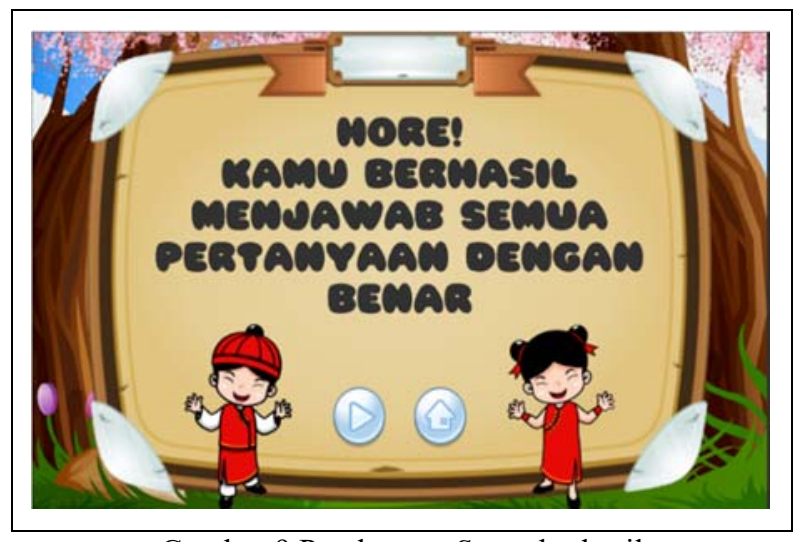

Gambar 9 Pembuatan Scene berhasil

Scene keenam adalah scene game over. Pada tampilan scene ini terdapat 2 tombol dan teks yang menyatakan bahwa pengguna memilih jawaban yang salah. Tombol pertama adalah tombl coba lagi yang berfungsi untuk memulai permainan dari awal lagi, tombol yang kedua adalah tombol kembali yang berfungsi untuk kembali ke menu utama. Untuk hasil pembuatan Scene game over bisa dilihat pada Gambar 10.

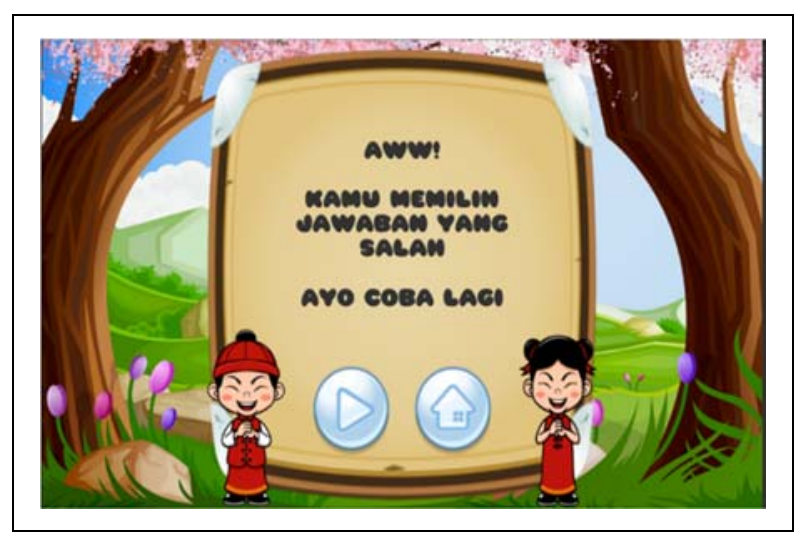

Gambar 10 Pembuatan Scene game over

Scene terakhir adalah scene tentang. Pada tampilan ini berisi pemberitahuan singkat tentang aplikasi dan pembuat aplikasi. Pada tampilan ini akan terdapat 1 tombol yaitu tombol kembali yang berfungsi untuk kembali ke menu utama aplikasi. Untuk hasil pembuatan Scene tentang bisa dilihat pada Gambar 11.

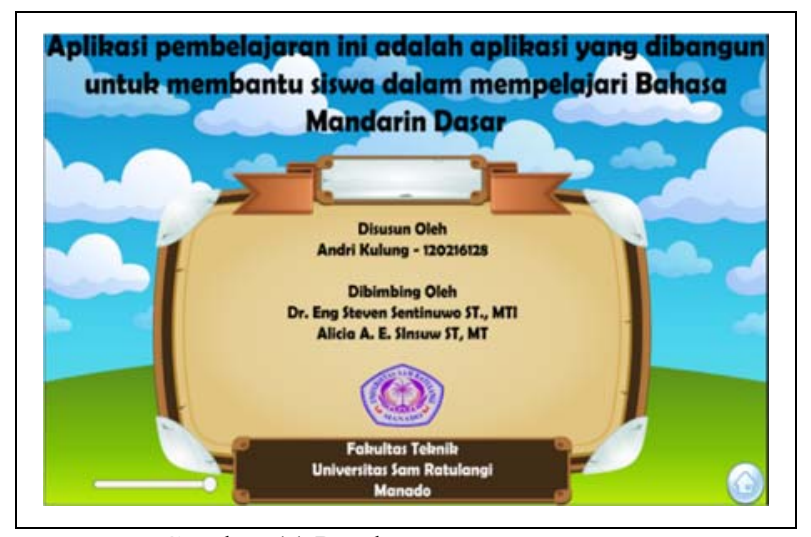

Gambar 11 Pembuatan Scene tentang

\section{B. Transition}

Sebelum melakukan deployment pengembang melakukan pengujian aplikasi dengan tujuan untuk memeriksa hasil output dan jika ada error pada setiap scene, dan tombol.

Tabel 6 Pengujian Scene menu utama

\begin{tabular}{|c|c|c|c|c|c|}
\hline $\begin{array}{c}\text { No } \\
\text {. }\end{array}$ & $\begin{array}{c}\text { Antarmu } \\
\text { ka yang } \\
\text { diuji }\end{array}$ & $\begin{array}{c}\text { Bagian } \\
\text { antarmu } \\
\text { ka yang } \\
\text { diuji }\end{array}$ & $\begin{array}{c}\text { Skenari } \\
\text { o } \\
\text { penguji } \\
\text { an }\end{array}$ & $\begin{array}{l}\text { Hasil yang } \\
\text { diharapkan }\end{array}$ & $\begin{array}{c}\text { Hasil } \\
\text { penguji } \\
\text { an }\end{array}$ \\
\hline 1 & $\begin{array}{l}\text { Scene } \\
\text { menu } \\
\text { utama }\end{array}$ & $\begin{array}{l}\text { Tombol } \\
\text { Menu } \\
\text { Belajar }\end{array}$ & $\begin{array}{l}\text { User } \\
\text { meneka } \\
\mathrm{n} \\
\text { tombol } \\
\text { Menu } \\
\text { Belajar }\end{array}$ & $\begin{array}{l}\text { Dapat } \\
\text { menampilk } \\
\text { an scene } \\
\text { belajar }\end{array}$ & Berhasil \\
\hline 2 & $\begin{array}{l}\text { Scene } \\
\text { menu } \\
\text { utama }\end{array}$ & $\begin{array}{l}\text { Tombol } \\
\text { Menu } \\
\text { Bermain }\end{array}$ & $\begin{array}{l}\text { User } \\
\text { meneka } \\
\mathrm{n} \\
\text { tombol } \\
\text { Menu } \\
\text { Bermai } \\
\mathrm{n}\end{array}$ & $\begin{array}{l}\text { Dapat } \\
\text { menampilk } \\
\text { an scene } \\
\text { bermain }\end{array}$ & Berhasil \\
\hline 3 & $\begin{array}{l}\text { Scene } \\
\text { menu } \\
\text { utama }\end{array}$ & $\begin{array}{l}\text { Tombol } \\
\text { Menu } \\
\text { Tentang }\end{array}$ & $\begin{array}{l}\text { User } \\
\text { meneka } \\
\mathrm{n} \\
\text { tombol } \\
\text { Menu } \\
\text { Tentang }\end{array}$ & $\begin{array}{l}\text { Dapat } \\
\text { menampilk } \\
\text { an scene } \\
\text { tentang }\end{array}$ & Berhasil \\
\hline 4 & $\begin{array}{l}\text { Scene } \\
\text { menu } \\
\text { utama }\end{array}$ & $\begin{array}{l}\text { Tombol } \\
\text { Menu } \\
\text { Keluar }\end{array}$ & $\begin{array}{l}\text { User } \\
\text { meneka } \\
\mathrm{n} \\
\text { tombol } \\
\text { Menu } \\
\text { Keluar }\end{array}$ & $\begin{array}{l}\text { Dapat } \\
\text { keluar dari } \\
\text { aplikasi }\end{array}$ & Berhasil \\
\hline
\end{tabular}

Hasil pengujian scene menu utama (lihat tabel 6) menunjukkan bahwa scene menu utama sudah berjalan dengan baik dan memberikan hasil sesuai dengan yang diharapkan.

Tabel 7 Pengujian Scene belajar

\begin{tabular}{|c|c|c|c|c|c|}
\hline No & $\begin{array}{c}\text { Antarmu } \\
\text { ka yang } \\
\text { diuji }\end{array}$ & $\begin{array}{c}\text { Bagian } \\
\text { antarmu } \\
\text { ka yang } \\
\text { diuji } \\
\end{array}$ & $\begin{array}{l}\text { Skenari } \\
\text { o } \\
\text { penguji } \\
\text { an }\end{array}$ & $\begin{array}{c}\text { Hasil } \\
\text { yang } \\
\text { diharapka } \\
\text { n }\end{array}$ & $\begin{array}{c}\text { Hasil } \\
\text { pengujia } \\
\mathrm{n}\end{array}$ \\
\hline 1 & $\begin{array}{l}\text { Scene } \\
\text { belajar }\end{array}$ & $\begin{array}{l}\text { Tombol } \\
\text { kelas } 1\end{array}$ & $\begin{array}{l}\text { User } \\
\text { meneka } \\
\mathrm{n} \\
\text { tombol } \\
\text { kelas 1 }\end{array}$ & $\begin{array}{l}\text { Dapat } \\
\text { menampil } \\
\text { kan } \\
\text { materi } \\
\text { dari kelas } \\
1\end{array}$ & Berhasil \\
\hline 2 & $\begin{array}{l}\text { Scene } \\
\text { belajar }\end{array}$ & $\begin{array}{l}\text { Tombol } \\
\text { kelas } 2\end{array}$ & $\begin{array}{l}\text { User } \\
\text { meneka } \\
\mathrm{n} \\
\text { tombol } \\
\text { kelas 2 }\end{array}$ & $\begin{array}{l}\text { Dapat } \\
\text { menampil } \\
\text { kan } \\
\text { materi } \\
\text { dari kelas } \\
2\end{array}$ & Berhasil \\
\hline 3 & $\begin{array}{l}\text { Scene } \\
\text { belajar }\end{array}$ & $\begin{array}{l}\text { Tombol } \\
\text { kelas } 3\end{array}$ & $\begin{array}{l}\text { User } \\
\text { meneka } \\
\mathrm{n} \\
\text { tombol } \\
\text { kelas } 3\end{array}$ & $\begin{array}{l}\text { Dapat } \\
\text { menampil } \\
\text { kan } \\
\text { materi } \\
\text { dari kelas } \\
3\end{array}$ & Berhasil \\
\hline 4 & $\begin{array}{l}\text { Scene } \\
\text { belajar }\end{array}$ & $\begin{array}{l}\text { Tombol } \\
\text { angka }\end{array}$ & $\begin{array}{l}\text { User } \\
\text { meneka } \\
\mathrm{n} \\
\text { tombol } \\
\text { angka } \\
\end{array}$ & $\begin{array}{l}\text { Dapat } \\
\text { menampil } \\
\text { kan isi } \\
\text { materi } \\
\text { angka }\end{array}$ & Berhasil \\
\hline 5 & $\begin{array}{l}\text { Scene } \\
\text { belajar }\end{array}$ & $\begin{array}{l}\text { Tombol } \\
\text { keluarga }\end{array}$ & $\begin{array}{l}\text { User } \\
\text { meneka }\end{array}$ & $\begin{array}{l}\text { Dapat } \\
\text { menampil }\end{array}$ & Berhasil \\
\hline
\end{tabular}




\begin{tabular}{|c|c|c|c|c|c|}
\hline & & & $\begin{array}{l}\mathrm{n} \\
\text { tombol } \\
\text { keluarg } \\
\mathrm{a}\end{array}$ & $\begin{array}{l}\text { kan isi } \\
\text { materi } \\
\text { keluarga }\end{array}$ & \\
\hline 6 & $\begin{array}{l}\text { Scene } \\
\text { belajar }\end{array}$ & $\begin{array}{l}\text { Tombol } \\
\text { tubuh }\end{array}$ & $\begin{array}{l}\text { User } \\
\text { meneka } \\
\mathrm{n} \\
\text { tombol } \\
\text { tubuh }\end{array}$ & $\begin{array}{l}\text { Dapat } \\
\text { menampil } \\
\text { kan isi } \\
\text { materi } \\
\text { tubuh }\end{array}$ & Berhasil \\
\hline 7 & $\begin{array}{l}\text { Scene } \\
\text { belajar }\end{array}$ & $\begin{array}{l}\text { Tombol } \\
\text { hewan }\end{array}$ & $\begin{array}{l}\text { User } \\
\text { meneka } \\
\mathrm{n} \\
\text { tombol } \\
\text { hewan }\end{array}$ & $\begin{array}{l}\text { Dapat } \\
\text { menampil } \\
\text { kan isi } \\
\text { materi } \\
\text { hewan }\end{array}$ & Berhasil \\
\hline 8 & $\begin{array}{l}\text { Scene } \\
\text { belajar }\end{array}$ & $\begin{array}{l}\text { Tombol } \\
\text { transport } \\
\text { asi }\end{array}$ & $\begin{array}{l}\text { User } \\
\text { meneka } \\
\mathrm{n} \\
\text { tombol } \\
\text { transpor } \\
\text { tasi }\end{array}$ & $\begin{array}{l}\text { Dapat } \\
\text { menampil } \\
\text { kan isi } \\
\text { materi } \\
\text { transporta } \\
\text { si }\end{array}$ & Berhasil \\
\hline 9 & $\begin{array}{l}\text { Scene } \\
\text { belajar }\end{array}$ & $\begin{array}{l}\text { Tombol } \\
\text { sekolah }\end{array}$ & $\begin{array}{l}\text { User } \\
\text { meneka } \\
\mathrm{n} \\
\text { tombol } \\
\text { sekolah }\end{array}$ & $\begin{array}{l}\text { Dapat } \\
\text { menampil } \\
\text { kan isi } \\
\text { materi } \\
\text { sekolah }\end{array}$ & Berhasil \\
\hline 10 & $\begin{array}{l}\text { Scene } \\
\text { belajar }\end{array}$ & $\begin{array}{l}\text { Tombol } \\
\text { percakap } \\
\text { an }\end{array}$ & $\begin{array}{l}\text { User } \\
\text { meneka } \\
\mathrm{n} \\
\text { tombol } \\
\text { percaka } \\
\text { pan }\end{array}$ & $\begin{array}{l}\text { Dapat } \\
\text { menampil } \\
\text { kan isi } \\
\text { materi } \\
\text { percakapa } \\
\mathrm{n}\end{array}$ & Berhasil \\
\hline 11 & $\begin{array}{l}\text { Scene } \\
\text { belajar }\end{array}$ & $\begin{array}{l}\text { Tombol } \\
\text { kosakata }\end{array}$ & $\begin{array}{l}\text { User } \\
\text { meneka } \\
\mathrm{n} \\
\text { tombol } \\
\text { kosakat } \\
\text { a } \\
\end{array}$ & $\begin{array}{l}\text { Dapat } \\
\text { menampil } \\
\text { kan isi } \\
\text { materi } \\
\text { kosakata }\end{array}$ & Berhasil \\
\hline 12 & $\begin{array}{l}\text { Scene } \\
\text { belajar }\end{array}$ & $\begin{array}{l}\text { Tombol } \\
\text { kembali }\end{array}$ & $\begin{array}{l}\text { User } \\
\text { meneka } \\
\mathrm{n} \\
\text { tombol } \\
\text { kembali }\end{array}$ & $\begin{array}{l}\text { Dapat } \\
\text { menampil } \\
\text { kan scene } \\
\text { menu } \\
\text { utama }\end{array}$ & Berhasil \\
\hline 13 & $\begin{array}{l}\text { Scene } \\
\text { belajar }\end{array}$ & $\begin{array}{l}\text { Tombol } \\
\text { suara }\end{array}$ & $\begin{array}{l}\text { User } \\
\text { meneka } \\
\mathrm{n} \\
\text { tombol } \\
\text { suara }\end{array}$ & $\begin{array}{l}\text { Dapat } \\
\text { mengelua } \\
\text { rkan } \\
\text { suara }\end{array}$ & Berhasil \\
\hline
\end{tabular}

Hasil pengujian scene belajar (lihat tabel 7) menunjukkan bahwa scene belajar sudah berjalan dengan baik dan memberikan hasil sesuai dengan yang diharapkan.

Tabel 8 Pengujian Scene bermain

\begin{tabular}{|c|c|c|c|l|c|}
\hline $\begin{array}{c}\text { No } \\
\cdot\end{array}$ & $\begin{array}{c}\text { Antarmu } \\
\text { ka yang } \\
\text { diuji }\end{array}$ & $\begin{array}{c}\text { Bagian } \\
\text { antarmu } \\
\text { ka yang } \\
\text { diuji }\end{array}$ & $\begin{array}{c}\text { Skenari } \\
\text { o } \\
\text { penguji } \\
\text { an }\end{array}$ & $\begin{array}{l}\text { Hasil yang } \\
\text { diharapkan }\end{array}$ & $\begin{array}{c}\text { Hasil } \\
\text { penguji } \\
\text { an }\end{array}$ \\
\hline 1 & $\begin{array}{l}\text { Scene } \\
\text { bermain }\end{array}$ & $\begin{array}{l}\text { Tombol } \\
\text { mulai } \\
\text { bermain }\end{array}$ & $\begin{array}{l}\text { User } \\
\text { meneka } \\
\mathrm{n} \\
\text { tombol } \\
\text { mulai } \\
\text { bermain }\end{array}$ & $\begin{array}{l}\text { Dapat } \\
\text { menampilk } \\
\text { an scene } \\
\text { mulai } \\
\text { bermain }\end{array}$ & Berhasil \\
\hline 2 & $\begin{array}{l}\text { Scene } \\
\text { bermain }\end{array}$ & $\begin{array}{l}\text { Tombol } \\
\text { kembali }\end{array}$ & $\begin{array}{l}\text { User } \\
\text { meneka } \\
\mathrm{n} \\
\text { tombol } \\
\text { kembali }\end{array}$ & $\begin{array}{l}\text { Dapat } \\
\text { menampilk } \\
\text { an scene } \\
\text { menu } \\
\text { utama }\end{array}$ & Berhasil \\
& & & & & \\
\hline
\end{tabular}

Hasil pengujian scene bermain (lihat tabel 8) menunjukkan bahwa scene bermain sudah berjalan dengan baik dan memberikan hasil sesuai dengan yang diharapkan.
Tabel 9 Pengujian Scene mulai bermain

\begin{tabular}{|c|c|c|c|c|c|}
\hline No & $\begin{array}{c}\text { Antarmu } \\
\text { ka yang } \\
\text { diuji }\end{array}$ & $\begin{array}{c}\text { Bagian } \\
\text { antarmu } \\
\text { ka yang } \\
\text { diuji }\end{array}$ & $\begin{array}{c}\text { Skenari } \\
\text { o } \\
\text { penguji } \\
\text { an }\end{array}$ & $\begin{array}{l}\text { Hasil yang } \\
\text { diharapkan }\end{array}$ & $\begin{array}{c}\text { Hasil } \\
\text { penguji } \\
\text { an }\end{array}$ \\
\hline 1 & $\begin{array}{l}\text { Scene } \\
\text { mulai } \\
\text { bermain }\end{array}$ & $\begin{array}{l}\text { Tombol } \\
\text { pilihan } \\
\text { jawaban }\end{array}$ & $\begin{array}{l}\text { User } \\
\text { meneka } \\
\mathrm{n} \\
\text { tombol } \\
\text { pilihan } \\
\text { jawaban }\end{array}$ & $\begin{array}{l}\text { Dapat } \\
\text { menampilk } \\
\text { an soal } \\
\text { gambar } \\
\text { selanjutnya } \\
\text {, scene } \\
\text { berhasil, } \\
\text { scene } \\
\text { game over }\end{array}$ & Berhasil \\
\hline 2 & $\begin{array}{l}\text { Scene } \\
\text { mulai } \\
\text { utama }\end{array}$ & $\begin{array}{l}\text { Tombol } \\
\text { kembali }\end{array}$ & $\begin{array}{l}\text { User } \\
\text { meneka } \\
\mathrm{n} \\
\text { tombol } \\
\text { kembali }\end{array}$ & $\begin{array}{l}\text { Dapat } \\
\text { menampilk } \\
\text { an scene } \\
\text { menu } \\
\text { utama }\end{array}$ & Berhasil \\
\hline
\end{tabular}

Hasil pengujian scene mulai bermain (lihat tabel 9) menunjukkan bahwa scene mulai bermain sudah berjalan dengan baik dan memberikan hasil sesuai dengan yang diharapkan.

Tabel 10 Pengujian Scene berhasil

\begin{tabular}{|c|c|c|c|c|c|}
\hline No & $\begin{array}{c}\text { Antarmu } \\
\text { ka yang } \\
\text { diuji }\end{array}$ & $\begin{array}{c}\text { Bagian } \\
\text { antarmu } \\
\text { ka yang } \\
\text { diuji }\end{array}$ & $\begin{array}{c}\text { Skenari } \\
\text { o } \\
\text { penguji } \\
\text { an }\end{array}$ & $\begin{array}{l}\text { Hasil yang } \\
\text { diharapkan }\end{array}$ & $\begin{array}{c}\text { Hasil } \\
\text { penguji } \\
\text { an }\end{array}$ \\
\hline 1 & $\begin{array}{l}\text { Scene } \\
\text { berhasil }\end{array}$ & $\begin{array}{l}\text { Tombol } \\
\text { coba } \\
\text { lagi }\end{array}$ & $\begin{array}{l}\text { User } \\
\text { meneka } \\
\mathrm{n} \\
\text { tombol } \\
\text { coba } \\
\text { lagi }\end{array}$ & $\begin{array}{l}\text { Dapat } \\
\text { menampilk } \\
\text { an scene } \\
\text { bermain }\end{array}$ & Berhasil \\
\hline 2 & $\begin{array}{l}\text { Scene } \\
\text { berhasil }\end{array}$ & $\begin{array}{l}\text { Tombol } \\
\text { kembali }\end{array}$ & $\begin{array}{l}\text { User } \\
\text { meneka } \\
\mathrm{n} \\
\text { tombol } \\
\text { kembali }\end{array}$ & $\begin{array}{l}\text { Dapat } \\
\text { menampilk } \\
\text { an scene } \\
\text { menu } \\
\text { utama }\end{array}$ & Berhasil \\
\hline
\end{tabular}

Hasil pengujian scene berhasil (lihat tabel 10) menunjukkan bahwa scene berhasil sudah berjalan dengan baik dan memberikan hasil sesuai dengan yang diharapkan.

Tabel 11 Pengujian Scene game over

\begin{tabular}{|c|l|l|l|l|c|}
\hline $\begin{array}{c}\text { No } \\
\cdot\end{array}$ & $\begin{array}{l}\text { Antarmu } \\
\text { ka yang } \\
\text { diuji }\end{array}$ & $\begin{array}{l}\text { Bagian } \\
\text { antarmu } \\
\text { ka yang } \\
\text { diuji }\end{array}$ & $\begin{array}{c}\text { Skenari } \\
\text { o } \\
\text { penguji } \\
\text { an }\end{array}$ & $\begin{array}{l}\text { Hasil yang } \\
\text { diharapkan }\end{array}$ & $\begin{array}{c}\text { Hasil } \\
\text { penguji } \\
\text { an }\end{array}$ \\
\hline 1 & $\begin{array}{l}\text { Scene } \\
\text { game } \\
\text { over }\end{array}$ & $\begin{array}{l}\text { Tombol } \\
\text { coba } \\
\text { lagi }\end{array}$ & $\begin{array}{l}\text { User } \\
\text { meneka } \\
\text { nen } \\
\text { tombol } \\
\text { coba } \\
\text { lagi }\end{array}$ & $\begin{array}{l}\text { Dapat } \\
\text { menampilk } \\
\text { an scene } \\
\text { bermain }\end{array}$ & Berhasil \\
\hline 2 & $\begin{array}{l}\text { Scene } \\
\text { game } \\
\text { over }\end{array}$ & $\begin{array}{l}\text { Tombol } \\
\text { kembali }\end{array}$ & $\begin{array}{l}\text { User } \\
\text { meneka } \\
\text { nenas } \\
\text { tombol } \\
\text { kembali }\end{array}$ & $\begin{array}{l}\text { Dapat } \\
\text { menampilk } \\
\text { an scene } \\
\text { menu } \\
\text { utama }\end{array}$ & Berhasil \\
\hline
\end{tabular}

Hasil pengujian scene game over (lihat tabel 11) menunjukkan bahwa scene game over sudah berjalan dengan baik dan memberikan hasil sesuai dengan yang diharapkan. 
Tabel 12 Pengujian Scene tentang

\begin{tabular}{|l|l|l|l|l|l|}
\hline $\begin{array}{l}\text { No } \\
\cdot\end{array}$ & $\begin{array}{l}\text { Antarmu } \\
\text { ka yang } \\
\text { diuji }\end{array}$ & $\begin{array}{l}\text { Bagian } \\
\text { antarmu } \\
\text { ka yang } \\
\text { diuji }\end{array}$ & $\begin{array}{l}\text { Skenari } \\
\text { o } \\
\text { penguji } \\
\text { an }\end{array}$ & $\begin{array}{l}\text { Hasil yang } \\
\text { diharapkan }\end{array}$ & $\begin{array}{l}\text { Hasil } \\
\text { penguji } \\
\text { an }\end{array}$ \\
\hline 1 & $\begin{array}{l}\text { Scene } \\
\text { tentang }\end{array}$ & $\begin{array}{l}\text { Informa } \\
\text { si } \\
\text { tentang } \\
\text { aplikasi }\end{array}$ & $\begin{array}{l}\text { User } \\
\text { meneka } \\
\mathrm{n} \\
\text { tombol } \\
\text { menu } \\
\text { tentang }\end{array}$ & $\begin{array}{l}\text { Dapat } \\
\text { menampilk } \\
\text { an } \\
\text { informasi } \\
\text { aplikasi }\end{array}$ & Berhasil \\
\hline 2 & $\begin{array}{l}\text { Scene } \\
\text { tentang }\end{array}$ & $\begin{array}{l}\text { Tombol } \\
\text { kembali }\end{array}$ & $\begin{array}{l}\text { User } \\
\text { meneka } \\
\mathrm{n} \\
\text { tombol } \\
\text { kembali }\end{array}$ & $\begin{array}{l}\text { Dapat } \\
\text { menampilk } \\
\text { an scene } \\
\text { menu } \\
\text { utama }\end{array}$ & Berhasil \\
& & & & & \\
\hline
\end{tabular}

Hasil pengujian scene tentang (lihat tabel 12) menunjukkan bahwa scene tentang sudah berjalan dengan baik dan memberikan hasil sesuai dengan yang diharapkan.

\section{KESIMPULAN DAN SARAN}

\section{A. Kesimpulan}

Dari penelitian yang dilakukan diperoleh kesimpulan:

1. Aplikasi pembelajaran Bahasa Mandarin Dasar telah berhasil dibuat sesuai permintaan pengguna dengan menggunakan metode Unified Software Development Process (USDP).

2. Aplikasi Pembelajaran Bahasa Mandarin Dasar sudah berjalan dengan seharusnya berdasarkan pengujian yang telah dilakukan.

3. Aplikasi pembelajaran Bahasa Mandarin Dasar dapat digunakan sebagi media belajar untuk anak tingkat sekolah dasar baik dalam jam sekolah maupun di luar jam sekolah.

B. Saran

Setelah dilakukan penelitian ini, disarankan:

1. Aplikasi yang telah dibuat dapat dimodifikasi supaya bisa digunakan dalam bentuk mobile agar pengguna dapat menggunakannya dimana saja dan kapan saja.

2. Aplikasi yang telah dibuat bisa dibuat dalam Bahasa pemrograman lain yang lebih bagus dalam hal grafik dan audio.

3. Materi yang telah dibuat agar bisa ditambah untuk kelas 4, 5, dan 6 tingkat sekolah dasar serta langkah-langkah penulisan Goresan Mandarin setiap kata.

4. Fitur bermain yang telah dibuat agar bisa ditambah permainan yang bersangkutan dengan Bahasa mandarin.

\section{DAFTAR PUSTAKA}

[1] Budhi, R. K., Yanggah, M. E., \& Hari, Y. (2016). RANCANG BANGUN APLIKASI PEMBELAJARAN AKSARA BAHASA MANDARIN UNTUK ANAK PRA SEKOLAH BERBASIS ANDROID. Proceeding SENDI_U.

[2] Dewi. (2015). IDENTIFIKASI GORESAN DASAR MANDARIN DENGAN METODE
MULTILAYER PERCEPTRON. CSRID Journal.

[3] Jati, D. I. (2013). APLIKASI PEMBELAJARAN DASAR FOTOGRAFI. Skripsi, Fakultas Ilmu Komputer UNIVERSITAS DIAN NUSWANTORO.

[4] Karouw, S. (2013). ANALISA DAN PERANCANGAN APLIKASI DORMITORY MANAGEMENT. Teknik Informatika Universitas Sam Ratulangi, 23.

[5] Kosasi, S. (2014). Pembuatan Aplikasi Pembelajaran Bahasa Mandarin Tingkat Dasar. STMIK Pontianak, 3.

[6] Nugroho, A. (2010). Rekayasa Perangkat Lunak Berorientasi Objek dengan Metode USDP. Yogyakrta: Penerbit Andi.

\section{SEKILAS TENTANG PENULIS}

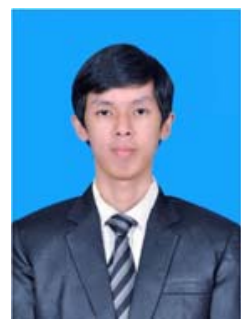

Sekilas tentang penulis dengan nama lengkap Andri Kulung, pada tanggal 02 Februari 1995 lahir di kota Manado, provinsi Sulawesi Utara. Penulis merupakan anak ke-2 dari 3 bersaudara dengan latar belakang pendidikan Sekolah Dasar Advent 1 Tikala Manado, Setelah lulus Melanjutkan ke Sekolah Menengah Pertama Advent 1 Tikala Manado. Kemudian melanjutkan ke Sekolah Menengah Atas SMA Pioneer Manado dan dinyatakan lulus pada tahun 2012 lalu melanjutkan ke Perguruan Tinggi di Universitas Sam Ratulangi Manado dengan mengambil Jurusan Elektro Program Studi Teknik Informatika. Pada tahun 2015 bulan Juli, penulis membuat Skripsi demi memenuhi syarat memperoleh gelar Sarjana (S1) dengan penelitian berjudul Perancangan Aplikasi Pembelajaran Bahasa Mandarin Dasar Menggunakan Metode Unified Software Development Process yang dibimbing oleh dua dosen pembimbing yaitu Dr. Eng. Steven R. Sentinuwo,ST.,MTI dan Alicia A. E. Sinsuw, ST., MT serta pada tanggal 14 Oktober 2016 penulis resmi lulus dari Program Studi Teknik Informatika Jurusan Elektro Fakultas Teknik Universitas Sam Ratulangi Manado dan menyandang gelar Sarjana Komputer dengan predikat Sangat Memuaskan. 